\title{
The Effect of Cryotherapy of Total Knee Arthroplasty Patients on Muscle Strength and Balance
}

\author{
Jin Park \\ Department of Physical Therapy, Drim Sol Hospital, Republic of Korea
}

Received March 31, 2021; Revised May 14, 2021; Accepted June 20, 2021

\section{Cite This Paper in the following Citation Styles}

(a): [1] Jin Park, "The Effect of Cryotherapy of Total Knee Arthroplasty Patients on Muscle Strength and Balance," International Journal of Human Movement and Sports Sciences, Vol. 9, No. 4, pp. 746 - 750, 2021. DOI: 10.13189/saj.2021.090419.

(b): Jin Park (2021). The Effect of Cryotherapy of Total Knee Arthroplasty Patients on Muscle Strength and Balance. International Journal of Human Movement and Sports Sciences, 9(4), 746 - 750. DOI: 10.13189/saj.2021.090419.

Copyright $\odot 2021$ by authors, all rights reserved. Authors agree that this article remains permanently open access under the terms of the Creative Commons Attribution License 4.0 International License

\begin{abstract}
In patients with total knee arthroplasty, the improvement of knee extensor muscle strength is an important factor in restoring stability, movement and function, and reducing pain. The purpose of this study was to investigate the effectiveness of cryotherapy to improve knee extensor strength and balance ability of total knee arthroplasty patients. In this study, 14 patients with total knee arthroplasty patients were recruited from a rehabilitation hospital. They were divided into two groups: a cryotherapy group $(n=7)$ and a control group $(n=7)$. They all received 30 minutes of continuous passive motion (CPM) and sit to stand training for 15 minutes and cryotherapy five times a week for two weeks. Knee extensor strength and balance ability were measured. Knee extensor strength was measured by Biodex system 3, balance ability was measured by Balancia software. To verify the difference in muscle strength and balance ability between groups, the pre-intervention value was set as a covariate and an analysis of covariance was performed. After the training period, the cryotherapy group showed a significant improvement in knee extensor muscle strength $(\mathrm{p}<0.05)$. There was no significant difference between groups in balance ability ( $>0.05)$. This study examined the effect of cryotherapy on muscle strength and balance ability after rehabilitation exercise in patients with total knee arthroplasty. The cryotherapy after rehabilitation exercise was found to have an effect on muscle strength improvement. However, it did not affect the balance ability. Therefore, it is recommended to improve muscle strength by applying cryotherapy after rehabilitation exercise for total knee arthroplasty patients.
\end{abstract}

Keywords Balance, Cryotherapy, Strength, Total Knee Arthroplasty.

\section{Introduction}

The knee joint is the most frequent site of degenerative arthritis as aging progresses, and exhibits forms such as pain and swelling, weakening of the lower extremity muscle strength, and a decrease in balance ability due to a decrease in proprioceptive sensory function [1]. Anti-inflammatory drugs and physical therapy are performed to control degenerative knee arthritis, but in severe patients, total knee arthroplasty (TKA) is performed in which an artificial joint is used to replace natural the knee joint [2]. Total knee arthroplasty is an effective method for decreasing pain, but adhesion occurs in the knee joint after surgery, and it decreases balance ability due to weakening of the lower extremity muscle strength, decreases functional abilities such as stair movement and gait [3][4][5].

In patients with total knee arthroplasty, the improvement of weakened knee extensor muscle strength is an important factor in restoring stability, movement and function, and reducing pain and swelling [6]. In a study by Rossi et al. [7], it was reported that strengthening of the knee joint extensor muscle was effective in inducing a symmetrical posture as well as reducing pain in patients with total knee arthroplasty. In a study by Resterschot et al. [8], it was verified that a symmetrical posture was 
induced and balance ability was improved by strengthening the knee joint extensor muscles in patients with total knee arthroplasty showing an asymmetric posture. Based on this, in the case of total knee arthroplasty patients, the shape of the asymmetric weight distribution is shown, which causes pain due to the increase in the compression force applied to the joint, so it can be seen that the strength of the knee joint extensor muscles needs to be strengthened during the rehabilitation process [9].

In addition, cryotherapy can be applied to reduce pain and swelling in patients with total knee arthroplasty. Cryotherapy is a method of rapidly cooling and spraying nitrogen in the atmosphere to below zero [10]. The effect of cryotherapy can lead to delay in proprioceptive deterioration rather than increase in blood flow, increase in joint movement due to temporary reduction in pain, and thus strengthen muscle strength [11]. Based on this, the previous study investigated that the application of cryotherapy to subjects with knee joint damage has the effect of strengthening the muscles around the knee joint [12][13].

Based on these previous studies, it is possible to know the effect of cryotherapy on muscle strength, but few studies have investigated the effect of applying cryotherapy on muscle strength and balance ability in Total Knee arthroplasty patients. Therefore, in this study, we tried to investigate the effect of cryotherapy on muscle strength and balance ability in total knee arthroplasty patients and provide clinical information.

\section{Methods}

\subsection{Subjects}

The study was conducted on a total of 14 patients admitted to the rehabilitation hospital located in J City, Korea, who understood the purpose of the study and wrote consent to participate in the study based on the Helsinki Declaration. The criteria for selection of the participants in the study were those who were diagnosed with osteoarthritis on one leg and received total knee arthroplasty within 3 weeks. Those who did not have pain in other areas except the knee, those who were able to stand up independently, allergy or circulation due to cold. Those with no disability or heart disease were excluded, and those with other surgery or disease of the lower extremities and patients with total knee arthroplasty due to external damage other than osteoarthritis were excluded. Prior to the study, subjects were randomly assigned to each group by drawing lots. There were 7 patients in the cryotherapy group, and 7 patients in the control group without cryotherapy. There was no significant difference between the groups for age, sex, height, weight, and visual analogue scale (VAS) of the subjects $(p>0.05)$. Table 1 shows the general characteristics of the subjects.

\subsection{Procedure}

Two groups of continuous passive exercise equipment (Artromot K-3 CPM, Ormed, Germany) were performed for 30 minutes, and then sit to stand training was performed for 15 minutes. After that, the cryotherapy group performed additional cryotherapy equipment (Crais, Century, Korea) for 3 minutes. It was conducted 5 times a week for a total of 2 weeks, and the amount of change was analyzed by measuring the knee extension muscle strength and balance ability before and after the intervention.

For the sit to stand training, the subjects were to sit on a height-adjustable bed (Bobath table, Kwang-won meditec, Korea) according to the height of the knee joints of the subjects, and then the hands were crossed in front of the chest. Seats were adjusted so that only half of the thighs of the subjects touched the bed, and gradually performed from $105^{\circ}$ to $75^{\circ}$ according to the knee flexion angle [14]. In order to minimize the subject's fatigue, they were allowed to rest for 30 seconds after 10 times, and stopped when they complained of pain or fatigue. In addition, it was emphasized verbally so that one therapist could perform stand-up training in a symmetrical position by being located at a close distance for the subject's safety.

Table 1. General characteristics of subjects $(n=14)$

\begin{tabular}{cccc}
\hline Characteristics & Cryotherapy group $\left(\mathrm{n}_{1}=7\right)$ & $\begin{array}{c}\text { Control } \\
\text { group }\left(\mathrm{n}_{2}=7\right)\end{array}$ & $\mathrm{p}$ \\
\hline Age (years) & $67.86 \pm 5.21^{\mathrm{b}}$ & $65.43 \pm 4.58$ & 0.37 \\
\hline Gender (M/F) & $2 / 5$ & $2 / 5$ & 0.75 \\
\hline Height (cm) & $163.29 \pm 8.04$ & $164.86 \pm 7.24$ & 0.70 \\
\hline Weight (kg) & $64.86 \pm 10.14$ & $63.43 \pm 5.59$ & $4 / 3$ \\
\hline Operation side (Rt/Lt) & $4 / 3$ & $3.43 \pm 1.27$ & 0.32 \\
\hline VAS $^{\mathrm{a}}(\mathrm{score})$ & $2.86 \pm 0.69$ & & \\
\hline
\end{tabular}

${ }^{a}$ Visual analogue scale, ${ }^{b}$ Mean \pm standard deviation 
Cryotherapy group was conducted using cryotherapy equipment. Subjects are allowed to stay in a treatment room with an ambient temperature of $25^{\circ} \mathrm{C}$ for 15 minutes to adjust to the temperature, then position them comfortably in a lying position. It was sprayed by setting it to $-20^{\circ} \mathrm{C}$. In order to prevent burns during cryotherapy, intensive injection was careful, and one therapist performed it for 3 minutes [10]. During cryotherapy, if the subject complained of pain or discomfort, the treatment was stopped. In the control group, in the same environment as the cryotherapy group, wind was injected for 3 minutes without setting the knee joint at low temperature using cryotherapy equipment.

\subsection{Assessment}

Biodex system 3 (Biodex Medical System, Shirley, Newyork, USA) was used to measure the muscle strength of the subjects' knee joint extensor muscles. Prior to the measurement, preliminary exercises were conducted twice, and the maximum value was used by measuring three times. In order to minimize muscle fatigue during the measurement, a rest period was provided for 30 seconds between measurements, and the measurement was performed within a pain-free range.

Balance ability measurement equipment (Balancia software, Mintosys, Korea) was used to measure the change in balance ability. This equipment is analyzed by connecting the Wii balance board that recognizes the subject's pressure center and the computer program (Balancia software) via bluetooth. Subjects looked at the front on the pressure plate, and after a standing position, their arms were folded and measured for 1 minute, and the average value was used after repeated measurements three times. For the safety of the subjects, the researcher assisted in a short distance. The variables used in this study were the average velocity dividing the moving distance of the COP by time, the path length representing the total moving distance of the COP, and the COP fluctuation of $95 \%$ based on the center of the standing posture. It is the area of 95\% sway area (Area 95\% COP), and the weight distribution of operated side.

\subsection{Statistical Analysis}

For statistical processing of the measured values of the subjects, it was analyzed through PASW 22.0 (SPSS Inc., Chicago, IL, USA). Normality test was performed through the kolmogorov-smirnov test, and an independent t-test was performed to test the homogeneity of the general characteristics of the cryotherapy group and the control group. Correspondence sample t-test was performed to analyze the before and after changes in muscle strength and balance ability of each group. To verify the difference in muscle strength and balance ability between groups, the pre-intervention value was set as a covariate and an analysis of covariance was performed. The statistical significance levels were 0.05 .

\section{Results}

\subsection{Knee Extension Muscle Strength}

In both groups, the muscle strength of the knee joint extensor muscle was significantly improved after the intervention compared to before the intervention $(p<0.05)$. In the comparison between groups, the cryotherapy group showed improved knee extensor muscle strength compared to the control group ( $\mathrm{p}<0.05)($ Table 2$)$.

\subsection{Balance}

In the cryotherapy group, all balance variables were compared with before and after the intervention. There was a significant difference $(\mathrm{p}<0.05)$. In the control group, there were statistically significant differences in path length, area 95\% COP, and weight distribution of the operated side $(\mathrm{p}<0.05)$. There was no difference between groups in all variables $(\mathrm{p}>0.05)($ Table 3$)$.

Table 2. Comparison of pre and post training outcome measures of muscle strength within and between groups

\begin{tabular}{ccccc}
\hline & & Cryotherapy group $\left(\mathrm{n}_{1}=7\right)$ & $\begin{array}{c}\text { Control } \\
\text { group }\left(\mathrm{n}_{2}=7\right)\end{array}$ & $\mathrm{p}$ \\
\hline & & & \\
\hline \multirow{3}{*}{ affected } & Knee extensors (Nm) & & $0.03^{\dagger}$ \\
& Pre & $23.40 \pm 9.64^{\mathrm{a}}$ & $24.64 \pm 5.74$ & $28.50 \pm 6.45$ \\
& Post & $29.93 \pm 11.17$ & $0.00^{*}$ & \\
\hline
\end{tabular}

${ }^{\mathrm{a}} \mathrm{Mean} \pm$ standard deviation, significant difference between pre and post intervention within the group $\left({ }^{*} \mathrm{p}<0.05\right)$, significant difference between the change values among the groups $\left({ }^{\dagger} \mathrm{p}<0.05\right)$ 
Table 3. Comparison of pre and post training outcome measures of balance ability within and between groups

\begin{tabular}{|c|c|c|c|c|}
\hline & & Cryotherapy group $\left(\mathrm{n}_{1}=7\right)$ & $\begin{array}{c}\text { Control } \\
\text { group }\left(\mathrm{n}_{2}=7\right)\end{array}$ & $\mathrm{p}$ \\
\hline Velocity average $(\mathrm{cm} / \mathrm{s})$ & $\begin{array}{l}\text { Pre } \\
\text { Post } \\
\text { p }\end{array}$ & $\begin{array}{c}2.54 \pm 0.49^{\mathrm{a}} \\
2.24 \pm 0.59 \\
0.02^{*}\end{array}$ & $\begin{array}{c}2.55 \pm 0.33 \\
2.31 \pm 0.30 \\
0.13\end{array}$ & 0.77 \\
\hline $\begin{array}{l}\text { Path length } \\
\qquad(\mathrm{cm})\end{array}$ & $\begin{array}{c}\text { Pre } \\
\text { Post } \\
\mathrm{p}\end{array}$ & $\begin{array}{c}75.50 \pm 13.64 \\
70.07 \pm 14.45 \\
0.01^{*} \\
\end{array}$ & $\begin{array}{c}80.91 \pm 10.52 \\
76.96 \pm 12.17 \\
0.01^{*} \\
\end{array}$ & 0.56 \\
\hline $\begin{array}{c}\text { Area } 95 \% \\
\left(\mathrm{~cm}^{2}\right)\end{array}$ & $\begin{array}{c}\text { Pre } \\
\text { Post } \\
\mathrm{p}\end{array}$ & $\begin{array}{c}2.32 \pm 0.61 \\
2.03 \pm 0.71 \\
0.02^{*}\end{array}$ & $\begin{array}{c}2.64 \pm 0.55 \\
2.37 \pm 0.50 \\
0.01^{*}\end{array}$ & 0.80 \\
\hline \multicolumn{5}{|c|}{ Weight distribution (\%) } \\
\hline Affected & $\begin{array}{l}\text { Pre } \\
\text { Post } \\
\text { p }\end{array}$ & $\begin{array}{c}44.78 \pm 0.89 \\
48.26 \pm 1.01 \\
<0.001^{*}\end{array}$ & $\begin{array}{c}44.86 \pm 1.56 \\
47.02 \pm 1.37 \\
0.01^{*}\end{array}$ & 0.07 \\
\hline
\end{tabular}

${ }^{\mathrm{a}}$ Mean \pm standard deviation, significant difference between pre and post intervention within the group $\left({ }^{*} \mathrm{p}<0.05\right)$

\section{Discussion}

This study was conducted to investigate the effect of cryotherapy on muscle strength and balance ability after rehabilitation exercise in total knee replacement patients and to provide clinical information.

As a result of comparing the changes in knee extensor muscle strength, both groups improved after the intervention than before. A study by Tung et al. [14] reported that standing training was effective in improving the strength of the extensor muscles of the knee joint. A study by Fujita et al. [15] also reported that repetitive standing up training is an effective method for improving knee extensor muscle strength. This is because the sit to stand is caused by the cooperation of the lower limb extensor sling in the closed chain, so if the sit to stand is repeatedly performed, the strength of the extensor sling muscles can be strengthened. In this study, since both groups performed sit to stand training and then cryotherapy, it is thought that the results of improvement in the muscle strength of the knee extensor muscles after intervention were considered.

As a result of the comparison of balance ability, the cryotherapy group showed improved results for all variables, and the control group showed improved results for variables other than the velocity average. In previous studies, it was investigated that sit to stand training is an effective method for improving balance ability than single-legged training [16][17]. It was reported that this was the result because the balance ability was required while the sit to stand was repeatedly moved from a low center of gravity to a high center of gravity from a wide base surface to a narrow base surface. In this study, it is believed that both groups performed sit to stand training, resulting in improved balance ability.

In the comparison between groups, the results of improved strength of the knee extensor muscles in the cryotherapy group were found. In the study of
Pietrosimone and Ingersoll [13], it was verified that the application of cryotherapy to subjects with knee joint injury has the effect of strengthening the muscles around the knee joint. It was suggested that the increase of the afferent input according to the temperature change reached the supraspinal level, interfering with the transmission of the inhibitory synaptic signal, resulting in increased muscle strength. In this study, the cryotherapy group showed an improvement in the strength of the knee extensor muscles compared to the control group.

There was no difference between groups in the comparison between groups for balance ability. Several factors are involved in controlling the balance ability, and the application of cryotherapy may have an effect on the improvement of muscle strength, but it is thought that other factors are not involved. In particular, Oliveira et al. [18] reported that cryotherapy had no effect on sensory nervous systems such as proprioceptive, but based on this, it is thought that there was no difference between groups in balance ability in this study.

In this study, cryotherapy was applied after rehabilitation exercise to improve lower extremity muscle strength and balance ability in total knee arthroplasty patients. In order to confirm the change in balance ability, it is necessary to verify the various factors necessary to maintain the balance. In this study, only the part of the knee extensor muscle strength was verified, so to verify the reason why cryotherapy did not affect balance ability. There are limitations to in addition, since the study was conducted on total knee arthroplasty patients undergoing rehabilitation in hospitals immediately after surgery, there is a limit to generalize to those who have passed the time after surgery. In addition, it is limited because the number of subjects participating in the study was small. Therefore, in future studies, the effects of cryotherapy should be tested for several subjects, such as the effect of cryotherapy on muscle strength and balance to the general subjects and total knee arthroplasty patients. 
This study examined the effect of cryotherapy on muscle strength and balance ability after rehabilitation exercise in patients with total knee arthroplasty. The application of cryotherapy after rehabilitation exercise was found to have an effect on muscle strength improvement. Therefore, it is recommended to improve muscle strength by applying cryotherapy after rehabilitation exercise for total knee arthroplasty patients.

\section{Conflicts of Interest}

The authors declare no conflicts of interest.

\section{REFERENCES}

[1] Christanell F, Hoser C, Huber R, et al. The influence of electromyographic biofeedback therapy on knee extension following anterior cruciate ligament reconstruction: a randomized controlled trial. Sports Medicine, Arthroscopy, Rehabilitation, Therapy \& Technology. 2012;4(1):41

[2] Strasser EM, Draskovits T, Praschak M, et al. Association between ultrasound measurements of muscle thickness, pennation angle, echogenicity and skeletal muscle strength in the elderly. Age(Dordr). 2013;35(6):2377-2388

[3] Bade MJ, Kohrt WM, Stevens-Lapsley JE. Outcomes before and after total knee arthroplasty compared to healthy adults. Journal of orthopaedic \& sports physical therapy. 2010;40(9):559-567

[4] Levinger P, Menz HB, Morrow AD, et al. Lower limb proprioception deficits persist following knee replacement surgery despite improvements in knee extension strength. Knee Surgery, Sports Traumatology, Arthroscopy. 2012;20(6):1097-1103

[5] Stevens-Lapsley JE, Balter JE, Kohrt WM, et al. Quadriceps and hamstrings muscle dysfunction after total knee arthroplasty. Clinical Orthopaedics and Related Research. 2010;468(9):2460-2468

[6] Yim SJ, Min KD, Lee YK, et al. Efficacy of physiotherapist after total knee arthroplasty. Knee Surgery \& Related Research. 2009;21(4):58-64

[7] Rossi MD, Everle T, Roche $\mathrm{M}$ et al. Closed-chain exercise after simultaneous bilateral knee replacement surgery: a case report. Physiotherapy Theory and Practice. 2010;26(3):204-214

[8] Regterschot GRH, Folkersma M, Zhang W et al. Sensitivity of sensor-based sit-to-stand peak power to the effects of training leg strength, leg power and balance in older adults. Gait Posture. 2014;39(1):303-307

[9] Christiansen CL, Bade MJ, Weitzenkamp DA, et al. Factors predicting weight-bearing asymmetry 1 month after unilateral total knee arthroplasty: a cross-sectional study. Gait Posture. 2013; 37(3):363-367

[10] Hong DJ, Choi KS, Park SB, et al. Changes in the Pressure Threshold of Myofascial Trigger Points Following Freezing Cold Air Application. Journal of the Korean Academy of Rehabilitation Medicine. 1999;23(1):134-139

[11] Pietrosimone BG, Hopkins JT, Ingersoll CD. The role of disinhibitory modalities in joint injury rehabilitation. Athletic Therapy Today. 2018;13(6):2-5

[12] Catlaw K, Arnold BL, Perrin DH. Effect of cold treatment on the concentric and eccentric torque-velocity relationship of the quadriceps femoris. Isokinetic and Exercise Science. 1996;5:157-160

[13] Pietrosimone BG, Ingersoll CD. Focal joint cooling increases the quadriceps central activation ratio. Journal of Sports Science. 2009; 27(8):873-879

[14] Tung FL, Yang YR, Lee CC, et al. Balance outcomes after additional sit-to-stand training in subjects with stroke: a randomized controlled trial. Clinical rehabilitation. 2010;24(6):533-542

[15] Fujita E, Taaffe DR, Yoshitake Y, et al. Repeated sit-to-stand exercise enhances muscle strength and reduces lower body muscular demands in physically frail elders. Experimental Gerontology. 2019;116:86-92

[16] Yamashita F, Iwamoto J, Osugi T, et al. Chair rising exercise is more effective than one-leg standing exercise in improving dynamic body balance: a randomized controlled trial. Journal of Musculoskeletal \& Neuronal Interactions. 2012;12(2):74-79

[17] E. Burhaein, B. K. Ibrahim, and R. Pavlovic, "The Relationship of Limb Muscle Power, Balance, and Coordination with Instep Shooting Ability: A Correlation Study in Under-18 Football Athletes," International Journal of Human Movement and Sports Sciences, vol. 8, no. 5, pp. 265-270, 2020. DOI: 10.13189/saj.2020.080515.

[18] Oliveira R, Ribeiro F, Oliveira J. Cryotherapy impairs knee joint position sense. International Journal of Sports Medicine. 2010;31(3):198-201 